\title{
Modeling the responses of Coffee (Coffea arabica L.) distribution to current and future climate change in Jimma Zone, Ethiopia
}

\author{
Fedhasa Benti Chalchissa ${ }^{1 *}$, Girma Mamo Diga ${ }^{2}$, Alemayehu Regassa Tolossa ${ }^{1}$ \\ ${ }^{1}$ Department of Natural Resource Management, Jimma University, Jimma, Ethiopia \\ ${ }^{2}$ Department of Climate Change and Biometrics, Ethiopia Agricultural Research Institute, Addis Ababa, Ethiopia
}

\begin{tabular}{|c|c|}
\hline ARTICLE INFO & ABSTRACT \\
\hline $\begin{array}{l}\text { Keywords: } \\
\text { Climatic factors } \\
\text { MaxEnt Model } \\
\text { Response optimization } \\
\text { Precipitation } \\
\text { Temperature } \\
\text { Article history } \\
\text { Submitted: 2021-09-06 } \\
\text { Accepted: 2022-01-22 } \\
\text { Available online: 2022-02-23 } \\
\text { Published regularly: Feb. } 2022 \\
\text { * Corresponding Author } \\
\text { Email address: } \\
\text { fedeesa@gmail.com }\end{array}$ & $\begin{array}{l}\text { Coffee arabica species have already been affected by climate change, with socioeconomic } \\
\text { implications. Smallholder farmers have encountered and will continue to confront issues } \\
\text { in maintaining their coffee plants' productivity. This study aimed to determine which bio- } \\
\text { climatic characteristics are most beneficial to coffee production in current and future } \\
\text { climate change scenarios. The responses of coffee distribution to climatic conditions were } \\
\text { studied under the current, moderate representative concentration (RCP4.5), and worst } \\
\text { representative concentration (RCP8.5) pathways using a bioclimatic modelling approach or } \\
\text { the Maxent model. Multiple regression models (path and response optimizers) were used } \\
\text { to parameterize and optimize the logistic outputs of plant distribution. Results showed that } \\
\text { climatic factors such as total precipitation, precipitation seasonality, and mean } \\
\text { temperature are the most important climatic factors in determining the success of } C \text {. } \\
\text { arabica farming. Under the current conditions, total precipitation significantly benefits } C \text {. } \\
\text { arabica whereas precipitation seasonality significantly affects it (P<0.001). In the current } \\
\text { condition, coffee responded neither negatively nor positively to the mean temperature, } \\
\text { but positively in RCP4.5 and RCP8.5. It would also respond positively to increased total } \\
\text { precipitation under RCP4.5 but negatively to rising precipitation under the RCP8.5. The } \\
\text { average five top-optimal multiple responses of } C \text {. arabica were } 75.8,77 \text {, and } 70 \% \text { for the } \\
\text { present, RCP4.5, and RCP8.5, respectively. The positive response of } C \text {. arabica to } \\
\text { bioclimatic variables in the RCP4.5 scenario is projected to be much bigger than in the } \\
\text { present and RCP4.5 scenarios ( }<\text { < } 0.001 \text { ). As precipitation and temperature-related } \\
\text { variables increase, the cultivation of } C \text {. arabica will increase by } 1.2 \% \text { under RCP4.5 but } \\
\text { decrease by } 5.6 \% \text { under RCP8.5. A limited number of models and environmental factors } \\
\text { were used in this study, suggesting that intensive research into other environmental } \\
\text { aspects is needed using different models. }\end{array}$ \\
\hline
\end{tabular}

How to Cite: Chalclchissa, F.B., Diga, G.M., Tolossa, A.R. (2022). Modeling of the responses of Coffee (Coffea arabica L.) distribution to current and future climate change in Jimma Zone, Ethiopia. Sains Tanah Journal of Soil Science and Agroclimatology, 19(1): 19-32. https://dx.doi.org/10.20961/stjssa.v19i1.54885

\section{INTRODUCTION}

Coffee is one of the most important major agricultural commodities traded across the world. It is mostly farmed by 25-30 million smallholder farmers in around 80 tropical nations (Aderolu et al., 2014). The countries include Ethiopia, Indonesia, Brazil, and Costa Rica as the best coffee-growing countries (Bliss, 2017). However, the majority of the global yield comes from the top five producing countries, including Brazil, Vietnam, Colombia, Indonesia, and Ethiopia (Coffee: World Markets and Trade, 2019; Funk et al., 2012). Ethiopia is the first $C$. arabica producer from Africa with a $39 \%$ share and is the $5^{\text {th }}$ country in the world with a nearly $2 \%$ share, and the annual coffee production of the country ranges from 200 to 250 thousand tons (Chauhan et al., 2015; Gray \& Brady, 2016).

Coffee is an important component of the overall economy and a major source of foreign currency for many coffeeproducing countries (Samper \& Quiñones-Ruiz, 2017). More than 125 million families rely on the coffee industry to better their living conditions (Bliss, 2017). In Ethiopia, coffee production and marketing play a basic part in the social and financial lives of the country's population (Alemayehu, 2015; Minten et al., 2014). It contributes about $44 \%$ of the country's 
foreign exchange (Aderolu et al., 2014), 10\% of the gross domestic product, and over $25 \%$ of the populace of Ethiopia are dependent on coffee for their livelihoods (Woldesenbet et al., 2015). Coffee is also ingrained in the socio-cultural fabric of the society. The consumption habits coffee are perfectly matched to modern lifestyles, making it an essential commodity in the daily lives of a vast section of the world's population (Vegro \& de Almeida, 2020). In Ethiopia, more than half of all the coffee produced in the country is drunk by the people, who utilize it not just to stimulate their minds but also to develop social capital and exchange information (Amamo, 2014; USDA Foreign Agricultural Service, 2019).

Bioclimatic predictors are the ones that are the most closely linked to a species' physiological process. They provide information on temperature and precipitation conditions on a monthly, seasonal, and annual basis (O'Donnel \& Ignizio, 2012). Seasonal climatic conditions affect the bioclimatology of many plants in different ways (Chiou et al., 2015). Preseason warmer winters, for example, delay budburst and flowering greatly, whereas cold winter temperatures significantly encourage most plants to release budburst and flowering (Svoboda \& Fuchs, 2017). Rainfall availability, in addition to temperature, has a significant impact on plant bioclimatology and is extremely important to climate change (Pohlan \& Janssens, 2010). It is the primary factor that frequently regulates plant bioclimatology (Song et al., 2016). Rainfall is responsible for dissolving minerals and carbohydrates and transporting them through the plants and controlling the degree of photosynthesis (Brázdil et al., 2015; Potopová et al., 2015).

Increases and decreases in these bioclimatic factors are equally relevant when dragged on a specific $C$. arabica (Moraes et al., 2010). Many coffee-growing areas have already seen temperatures much beyond the mild temperature range of 18 to $22^{\circ} \mathrm{C}$, which is normally best for coffee production with annual total precipitation of 800 to $1200 \mathrm{~mm}$ (Camargo, 2010). Temperatures are expected to rise by about 2 degrees Celsius on average globally until the mid-century (Steffen et al., 2018). This rising temperature scenario may cause the current coffee locations to change. The higher temperatures, extended droughts, and severe rains and frosts have a variety of effects on coffee production, ranging from shrinking coffee-growing regions to increasing pest and disease pressure (Bunn, 2015). It can limit the crop plant's physiological range, limiting its distribution to varying degrees (Deribe, 2019; Somarriba \& López Sampson, 2018). Under high temperatures, C. arabica is exposed to high irradiance and absorbs far more energy than what is required for photosynthesis, resulting in energy overpressure and, commonly, leaf overheating (Moraes et al., 2010). Significant coffee crop production losses and substantial reductions in areas suitable for the coffee landscape will also be caused by the end of the current century (Moat et al., 2017) and even the extinction of wild populations of $C$. arabica are all related to the impacts of rising air temperatures (Davis et al., 2012).

Despite Ethiopia's significant socio-economic benefits from coffee, climate change's impact on C. arabica farming has gotten little attention until recently. Examining the impact of bioclimates across time is therefore beneficial to species conservation. This can give biologists and ecologists more useful and multi-scaled climate data to assist studies on species' responses to the changing climatic conditions. The goal of this study was to apply machine learning algorithms to evaluate the reaction of the $C$. arabica distribution to bioclimate variables and determine the best setting for each bioclimatic factor for present and future climate change scenarios.

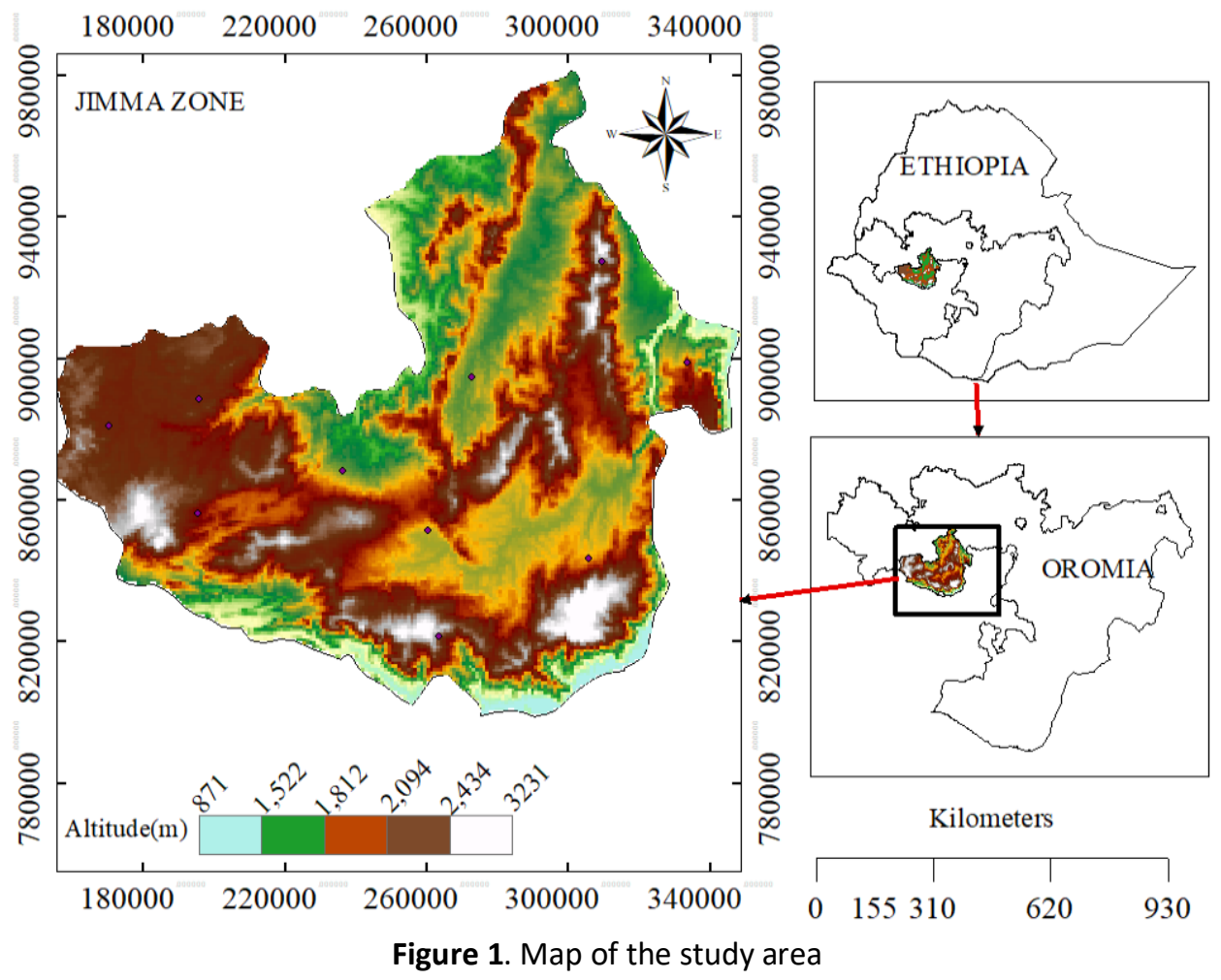




\section{METHODOLOGY}

\subsection{Description of the study area}

The study was conducted in the Jimma Zone in Oromia Regional State, Ethiopia. Jimma is one of the country's major coffee-producing administrative zones. It is located 357 kilometers southwest of Addis Ababa. It is situated between $7.13^{\circ}$ and $8.56^{\circ} \mathrm{N}$ and $35.49^{\circ}$ and $38.38^{\circ} \mathrm{E}$ and has an elevation of 871-3231 $\mathrm{m}$ above sea level (Fig. 1).

Southwest Ethiopia has a tropical climate. However, because of the highlands (mainly over 1000 meters), it may be categorized as cool-tropical (Moat et al., 2017). The Jimma zone is characterized by a cool-tropical highland climate featuring heavy precipitation, warm temperatures, and a protracted rainy season. According to conventional agroecological zonation, there are three primary climatic zones, namely subtropical, tropical, and temperate zones, with 78 , 10 , and $12 \%$ coverage, respectively (National Meteorological Services Agency, 2005). The annual rainfall ranges from 1,200 $\mathrm{mm}$ to $2,500 \mathrm{~mm}$, with an average annual minimum and maximum temperatures of $11^{\circ} \mathrm{C}$ and $28^{\circ} \mathrm{C}$, respectively. Twelve of the twenty districts are highly notable for coffee production, demonstrating how vital the crop is to local and rural residents' livelihoods (Diro et al., 2019).

\subsection{Data collection}

\subsubsection{Species location data}

Two hundred twenty-four geographical coordinates or points of data where $C$. arabica are found were acquired through field surveys, literature reviews, and online sources; the Global Biodiversity Information Facility (GBIF) database, which can be accessed at http://www.gbif.org. This gathered location data was organized into three columns: species, longitude, and latitude, as stated by Kwon et al. (2019). The spatially auto-correlated data was tested to reduce numerous data points within 25 square kilometers into a single point to avoid the model's overfitting to environmental bias (Boria et al., 2014).

\subsubsection{Climatic data}

The Paleoclimate database was used to retrieve historical bio-climatic variables recorded at a high resolution of 30 seconds between 1979 and 2013. It's a free resource that displays surface temperature and precipitation gauges from the General Circulation Model at http://www.paleoclim.org. The GCM outputs were scaled down to include verified sources that can shed light on the recent past and biological proxies, and biases were addressed (Brown et al., 2018; Karger et al., 2017). However, future bioclimatic data that was recorded from 2041 to 2060 was downloaded from the WorldClim dataset, available at http://www.worlclim.org. This data was also produced by global climate models (GCMs) (Fick \& Hijmans, 2017). The RCP4.5 and RCP8.5 climate change scenarios from the Intergovernmental Panel on Climate Change's fifth assessment report (Intergovernmental Panel on Climate Change, 2014) were used for this study. The averages of bioclimatic variables were obtained from four models, such as ACCESS1-O; GFDL-ESM2G; HadGEM2-AO, and HadGEM2-ES). These models have a low degree of interdependency, allowing for a more accurate representation of uncertainty in climate projections (Karger et al., 2017).

These variables included: Annual mean temperature (Bio1), Mean diurnal range (Bio2), Isothermality (Bio3), Temperature seasonality (Bio4), Max temperature of the warmest month (Bio5), Min temperature of the coldest month (Bio6), Temperature annual range (Bio7), Mean temperature of the wettest quarter (Bio8), Mean temperature of the driest quarter (Bio9), Mean temperature of warmest quarter (Bio10), Mean temperature of coldest quarter (Bio11), Total annual precipitation (Bio12), Precipitation of wettest month (Bio13), Precipitation of driest month (Bio14), Precipitation seasonality (Bio15), Precipitation of wettest quarter (Bio16), Precipitation of driest quarter (Bio17), Precipitation of warmest quarter (Bio18), and Precipitation of coldest quart (Bio19).

\subsection{Data preparation}

Prior to machine learning, each dataset was pre-arranged according to the format of the Maxent model. Global environmental layers are raster files, so that they were first extracted into a study area before being converted to the format of the American Standard Code for Information Interchange (ASCII). The correlation between the 19 bioclimatic variables was investigated, and then, 9 variables having absolute values of the correlation coefficient of less than $0.5(R<0.5)$ was maintained for model training (Phillips \& Dudík, 2008). Both environmental variables and sample species' geographical location were then, translated into a projected coordinate system, using ArcMap software (Paquit, 2019). The two sets of data were uploaded when all of the necessary steps had been completed, and the Maxent model was run following the steps described in Paquit (2019).
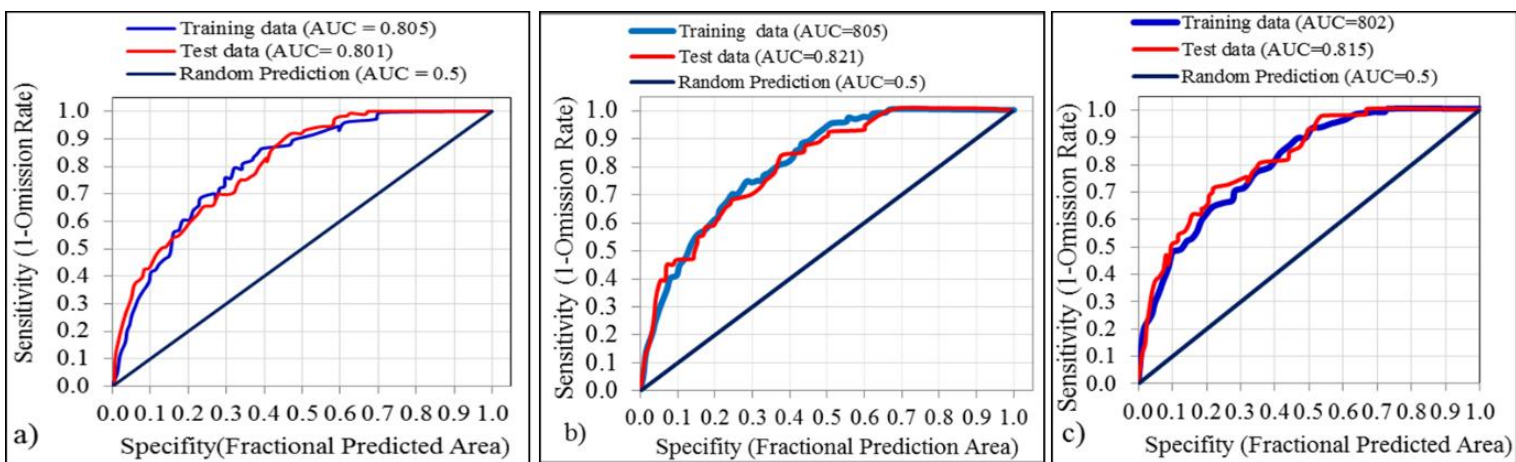

Figure 2. Model performance in discriminating affected and none affected coffee habitat by climatic factors associated with Current (a) and 2050s under the RCP4.5 scenario (b) and RCP8.5 scenario (c) 


\subsubsection{Model validation}

The model's performance was assessed by plotting a sensitivity vs specificity graph following the procedure of . Phillips et al. (2017) and producing ROC statistics. The Receiver Operating Characteristic (ROC) curve is defined using the Area Under the Curve (AUC), which ranged from 0.5 to 1 (Halligan et al., 2015). According to Pearson and Dawson (2003), the AUC threshold was classified into five categories to characterize model performance in scientific methods. The model's performance is said to be "excellent or perfect" if the value of AUC is equal to 1, "very good" if the AUC's value is less than 1 and greater than or equal to 0.9, "good" if the AUC's value is less than 0.9 and greater or equal to 0.8 , "fair" if the AUC's value is less than 0.8 and greater or equal to 0.7 , and "poor or fail" if the AUC's value is less than 0.7. A random ranking has a mean of 0.5 AUC value. Thus, a higher AUC value shows the greatest model performance for distinguishing between affected and non-affected species' environments (Mas et al., 2013).

\subsection{Statistical analyses}

After modeling the species distribution, the logistic outputs of the species distribution from the Maxent model were subjected to multiple regression models using Amos and Minitab software to assess coffee plant responses to combined effects of bioclimatic variables and to determine the optimal setting of these parameters for the coffee plants.

\subsubsection{Multiple responses analyses}

Multiple response analyses were carried out for $C$. arabica as a response variable and bio-climatic factors as explanatory variables, reflecting plant dispersion under current and future bioclimatic change. This statistical study was conducted utilizing the Analysis of Moment Structures (Amos) program version 23. The chi-square statistic ( $\mathrm{Chi}^{2}$ and $\mathrm{P}$-value) were employed to assess the quality of model fit, where the lower the chi-square and the higher the P-values associated with the chi-square, the better the model fit (Cuneen \& Tobar, 2015; McHugh, 2013).

\subsubsection{Multiple responses optimization}

A multiple regression optimizer was used to evaluate the best responses of $C$. arabica to bio-climatic factors using Minitab's response optimizer tool. Response optimization is a technique for discovering the best combination of factors and settings for a single or a series of response variables. This is important for determining the impacts of various bioclimatic factors on $C$. arabica cultivation. For the optimization, plots were created for $C$. arabica vs bioclimatic variable based on current, RCP4.5, and RCP8.5 scenarios of the 2050s. Before computing response optimization for each climatic scenario, the goodness of fit of the model was assessed using Rsquared. R-Squared is a statistical measure of fit that indicates how much variation in a dependent variable in a regression model is explained by the variation in independent variable(s) (Gelman et al., 2019; Wang et al., 2017). The goodness-of-fit test is characterized by the difference between the actual and predicted values in the model description (Wan \& Davis, 2020). If the R-squared value is less than 0.3 , it is typically regarded to have no or very weak impact size. If the Rsquared value is greater than 0.3 and less or equal to 0.5 , the effect size is deemed weak or lower; if the R-squared value is greater than 0.5 and less or equal to 0.7 , the impact size is considered moderate; and if the R-squared value is greater than 0.7, the impact size is considered strong (Moore, 2001).

\section{RESULTS}

\subsection{Models' performance evaluations results 3.1.1. MaxEnt model}

The validation test results showed that the model worked well, with accuracy levels of more than $80 \%$ under all of the climate change scenarios studied. Its accuracy level was classified as "good" as enough to discriminate between coffee settings influenced by climate change and those that were not, according to the findings (Fig. 2). The model training and test outcomes exhibited mean AUC values of 0.805 (80.5\%) and $0.801(80.1 \%)$, respectively, under the present conditions. Similarly, the mean AUC values for the model training and test outcomes using the RCP4.5 scenario were 0.805 (80.5\%) and 0.821 (82.1\%), respectively, whereas they were $0.802(80.2 \%)$ and 0.815 (81.5\%) for the RCP8.5 scenario.

Table 1. Contributions of bioclimatic variables to the Maxent model as a percentage

\begin{tabular}{|c|c|c|c|c|}
\hline \multirow{2}{*}{ Code } & \multirow{2}{*}{ Bioclimatic Variables } & \multirow{2}{*}{ Current } & \multicolumn{2}{|c|}{ 2050s } \\
\hline & & & RCP4.5 & RCP8.5 \\
\hline Bio1 & Annual mean temperature & 3.7 & 7.4 & 10.3 \\
\hline Bio3 & Isothermality & 5.7 & 3.3 & 3.1 \\
\hline Bio4 & Temperature seasonality & 3.1 & 4.2 & 0.4 \\
\hline Bio7 & Annual temperature range & 0.5 & 0.9 & 1.2 \\
\hline Bio12 & Total annual precipitation & 55.1 & 62.8 & 64.8 \\
\hline Bio13 & Precipitation of the wettest month & 0.9 & 5.4 & 5.5 \\
\hline Bio15 & Precipitation seasonality & 17 & 8.1 & 8.8 \\
\hline Bio18 & Precipitation of the warmest quarter & 5.4 & 2.2 & 1 \\
\hline Bio19 & Precipitation of the warmest quarter & 8.5 & 5.7 & 4.9 \\
\hline
\end{tabular}




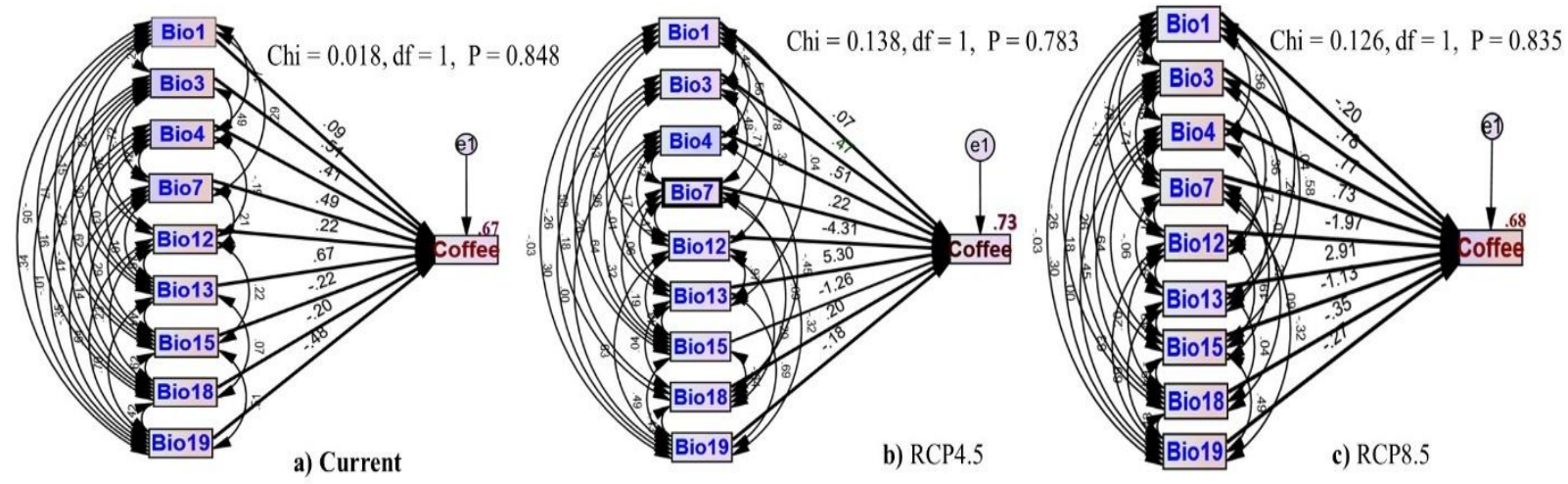

Note: The numbers displayed on curved and straight arrows represent the coefficient of multi-co-linearity among the bioclimatic variables and standardized regression weights between the explanatory and the response variables, respectively.

Figure 3. Path diagram showing the effect of bioclimatic variables on the $C$. arabica distributions under the scenarios of Current (a) RCP4.5 (b) and RCP8.5 (c).

\subsubsection{Multiple regression models}

Path Model: A Chi-squared analysis result is depicted in Fig. 3. The Chi-square and P-values in the top right corner of the diagram and the R-square values over the heads of response variables represent the model's goodness of fit. Under the present and 2050s RCP4.5 and RCP8.5 climate scenarios, chi-square values were determined to be 0.18 , 0.138 , and 0.126 , respectively. For the current and 2050 RCP4.5 and RCP8.5 climate scenarios, the corresponding $\mathrm{p}$ values are $0.848,0.783$, and 0.835 , respectively. This indicated that the unconstrained model fitted the data very well. Because all of the Chi-square was minimal and the $p$ values were statistically insignificant, the model's fit test was appropriate to simulate $C$. arabica's distribution response to bioclimatic variables (McHugh, 2013).

Response optimizer Model: Similarly, the model's quality of fit to simulate the response and predictor variables is indicated by the R-square analysis. As a result, the R-squared values for current, RCP4.5, and RCP8.5, respectively, were $64.98 \%, 70.14 \%$, and $73.75 \%$, indicating that bioclimatic had a moderate impact on $\mathrm{C}$. arabica in Current and a large impact in RCP4.5 and RCP8.5 climate change scenarios. To put it another way, the error variance of coffee under each of the three climatic conditions would be around 33\%, 27\%, and $32 \%$ of the variation in the coffee itself, respectively.

\subsection{Climatic variables' contributions to the model's performance}

Table 1 demonstrates how each bioclimatic variable affects the model's performance under the present and RCP4.5 and RCP8.5 of the 2050s climate change scenarios. The results revealed that each of the variables offered the most important information for the model's performance under all climate change scenarios. In the current and 2050s RCP4.5 and RCP8.5 climate change scenarios, the percentage contributions of total precipitation (Bio12) were determined to be $55.1 \%, 62.8 \%$, and $64.8 \%$, respectively. The percentage contributions of precipitation seasonality (Bio15) were determined to be $17 \%, 8.1 \%$, and $8.8 \%$, respectively, under present and 2050s RCP4.5 and RCP8.5. Annual mean temperature (Bio) contributed $3.7 \%, 7.4 \%$, and $10.3 \%$ under current and predicted 2050s RCP4.5 and RCP8.5, respectively. This suggests that precipitation-related factors, in general, had a much bigger influence on C. arabica from 1979 to 2013, and will continue to have a significantly greater impact on the crop until the next 2050s, with total precipitation and precipitation seasonality in particular.

\subsection{Responses of Coffee (Coffea arabica L.) to current and future bioclimatic factors \\ 3.3.1. Current response analyses}

The model's diagnostic results reveal an asymmetric relationship between coffee and bioclimatic parameters, with coffee having a positive relationship with some bioclimatic factors but a negative relationship with others. Coffee has been shown to be negated and significantly associated with precipitation in the warmest quarter (Bio18) and the coldest quarter (Bio19) over the last three decades, with maximum probability values of-0.01 and $-0.001(P<0.05)$, respectively. This means that when the Bio18 and Bio19 variables were increased by one unit, $C$. arabica declined by $1 \%$ and $0.1 \%$, respectively $(P<0.05)$. Changes in Bio18, in particular, exhibited a significant negative impact on $C$. arabica. It also exhibited a non-significant negative association with the yearly mean temperature (Bio1) at $\mathrm{P}<0.05$. Temperature seasonality (Bio4), annual temperature range (Bio7), total precipitation (Bio12), and precipitation seasonality (Bio15) were all shown to have a substantial and positive relationship with $C$. arabica. The maximum likelihoods' values of the variables were $0.001,0.008,0.001$, and 0.018, for Bio4, Bio7, Bio12, and Bio15, respectively. When Bio4, Bio7, Bio12, and Bio15 were grown in parallel to one unit, $C$. arabica distribution grew by $0.1 \%, 0.8 \%, 0.1 \%$, and $1.8 \%$, respectively (Table 2). Bio15 was the most important variable that trained the distribution of $C$. arabica, while Bio7 was the second most important variable.

The path model, on the other hand, quantifies the magnitude of each influence using normalized regression weight. The negative standardized regression weights between the coffee plant and explanatory variables were estimated to be $-0.22,-0.20$, and -0.48 for Bio15, Bio18, and Bio19, 
Table 2. C. arabica and bioclimatic factors multiple regression weights in Current (1979-2013)

\begin{tabular}{|c|c|c|c|c|c|}
\hline $\begin{array}{l}\text { Predictor } \\
\text { Variables }\end{array}$ & $\begin{array}{l}\text { Maximum } \\
\text { Likelihood }\end{array}$ & $\begin{array}{c}\text { Standardized } \\
\text { R weight }\end{array}$ & Standard Error. & Critical Ratio. & Sign \\
\hline Bio1 & -0.014 & 0.09 & 0.012 & -1.500 & 0.126 \\
\hline Bio3 & 0.070 & 0.51 & 0.018 & 1.949 & 0.156 \\
\hline Bio4 & 0.001 & 0.41 & .000 & 7.580 & $* * *$ \\
\hline Bio7 & 0.008 & 0.49 & 0.002 & 4.397 & $* * *$ \\
\hline Bio12 & 0.001 & 0.22 & .000 & 6.88 & $* * *$ \\
\hline Bio13 & 0.000 & 0.67 & .000 & 0.100 & 0.924 \\
\hline Bio15 & 0.018 & -0.22 & 0.003 & 5.275 & $* * *$ \\
\hline Bio18 & -0.010 & -0.20 & 0.00 & -2.893 & $0.015^{*}$ \\
\hline Bio19 & -0.001 & -0.48 & 0.001 & -3.639 & $* * *$ \\
\hline
\end{tabular}

Note: $* * * * *$, and $*$ indicates a significant relationship between response and explanatory variable at $\boldsymbol{\alpha}=0.001,0.01$, and 0.05 , respectively.

respectively, under current climatic conditions, whereas the positive standardized regression weights, respectively, for Bio1, Bio3, Bio4, Bio12, and Bio19 were 0.09, 0.51, 0.47, 0.49, 0.22 , and 0.67 (Table 2). When the explanatory factors rose by one standard deviation, the values of the standardized regression weights of the coffee distribution estimates dropped for negative values and rose for positive regression weights.

\subsubsection{Future responses analysis under RCP4.5 and RCP8.5 climate scenarios}

In the RCP4.5, the association between $C$. arabica and bioclimatic variables was estimated to be significantly stronger $(P<0.05)$, except for total precipitation (Bio12) and precipitation in the warmest quarter (Bio18). In the next 2050s, C. arabica is expected to fall, with an increase in precipitation seasonality (Bio15), as well as precipitation in the warmest (Bio18), and coldest (Bio19) quarters. The maximum likelihood's values of Bio15, Bio18, and Bio19 were estimated to be $-0.018,-0.001$, and -0.001 , respectively (Table 2 ). This suggests that $C$. arabica's cultivation will be significantly decreased by $1.8 \%, 0.1 \%$, and $0.1 \%$, respectively, when Bio15, Bio18, and Bio19 increase. On the other hand, $C$. arabica was promisingly associated with annual mean temperature (Bio1), isothermality (Bio3), temperature seasonality (Bio4), annual temperature ranges (Bio7), total precipitation (Bio12), and precipitation of the wettest months (Bio13). The maximum likelihood values for Bio1, Bio3, Bio4, Bio7, Bio12, and Bio13 were predicted to be 0.006, 0.055, $0.001,0.096$, and 0.005 , respectively (Table 2 ), suggesting that percentage increases of $C$. arabica will be $0.6,5.5,0.1$, $9.6,0.2$, and 0.5 , respectively, when these variables are increased by one unit. Among these bioclimatic variables, annual temperature ranges (Bio7) will be the most variable factor in increasing $C$. arabica cultivation, followed by isothermality (Bio3).

Table 3. C. arabica and bioclimatic factors multiple regression weights in RCP4.5 and RCP8.5 (2041-2060)

\begin{tabular}{|c|c|c|c|c|c|c|}
\hline $\begin{array}{l}\text { Predictor } \\
\text { variables }\end{array}$ & Scenarios & $\begin{array}{l}\text { Maximum } \\
\text { likelihood }\end{array}$ & $\begin{array}{l}\text { Standard } \\
\text { R. weight }\end{array}$ & Standard Error & Critical Ratio & Sign \\
\hline \multirow{2}{*}{ Bio1 } & RCP4.5 & 0.006 & 0.07 & 0.007 & 3.598 & $* * *$ \\
\hline & RCP8.5 & 0.019 & 0.20 & 0.014 & -3.394 & $0.01 * *$ \\
\hline \multirow{2}{*}{ Bio3 } & RCP4.5 & 0.055 & 0.47 & 0.008 & 6.506 & $* * *$ \\
\hline & RCP8.5 & -0.046 & 0.20 & 0.008 & -5.766 & $* * *$ \\
\hline \multirow{2}{*}{ Bio4 } & RCP4.5 & 0.001 & 0.51 & 0.00 & 8.856 & $* * *$ \\
\hline & RCP8.5 & 0.001 & 0.78 & 0.00 & 0.685 & 0.362 \\
\hline \multirow{2}{*}{ Bio7 } & RCP4.5 & 0.096 & 0.22 & 0.025 & 3.758 & $* * *$ \\
\hline & RCP8.5 & 0.063 & 0.73 & 0.024 & 2.626 & $0.01 * *$ \\
\hline \multirow{3}{*}{ Bio12 } & RCP4.5 & 0.002 & -4.31 & 0.001 & -3.048 & $0.01 * *$ \\
\hline & RCP8.5 & -0.004 & -1.97 & 0.00 & -4.572 & $* * *$ \\
\hline & RCP4.5 & 0.005 & 5.30 & 0.001 & 2.50 & 0.621 \\
\hline Bio13 & RCP8.5 & -0.007 & 2.91 & 0.001 & -5.909 & $* * *$ \\
\hline \multirow{2}{*}{ Bio15 } & RCP4.5 & -0.018 & 1.26 & 0.003 & -5.275 & $* * *$ \\
\hline & RCP8.5 & 0.02 & 1.13 & 0.003 & 6.178 & $* * *$ \\
\hline \multirow{2}{*}{ Bio18 } & RCP4.5 & -0.001 & -0.35 & 0.00 & -1.298 & 0.122 \\
\hline & RCP8.5 & -0.001 & 0.20 & 0.00 & -2.838 & $0.01 * *$ \\
\hline \multirow{2}{*}{ Bio19 } & RCP4.5 & -0.001 & -0.18 & 0.00 & -2.456 & $0.014^{*}$ \\
\hline & RCP8.5 & -0.001 & -0.21 & 0.00 & -3.762 & $* * *$ \\
\hline
\end{tabular}

Note: $* * *, * *$, and $*$ indicates a significant relationship between response and explanatory variable at $\boldsymbol{\alpha}=0.001,0.01$, and 0.05 , respectively. 


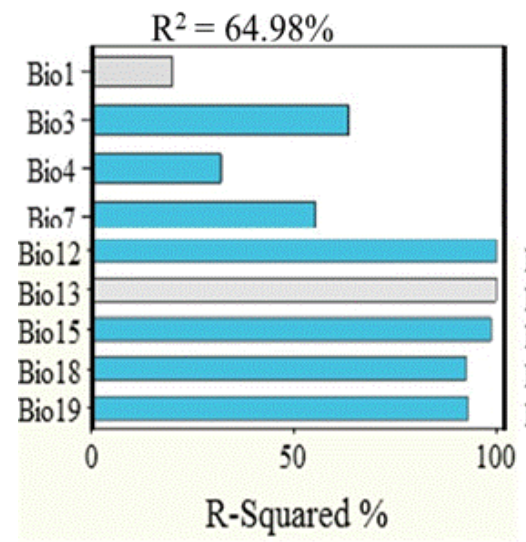

a) Current

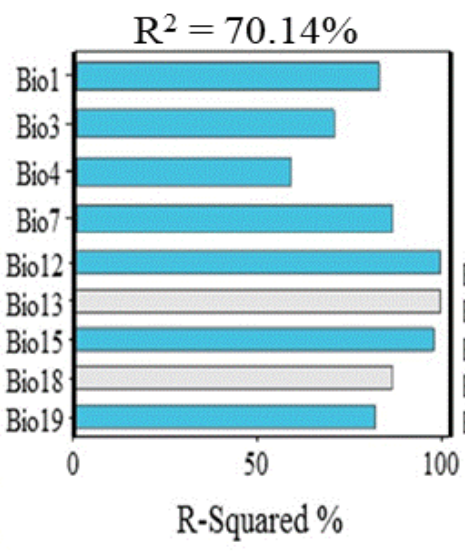

b) RCP4.5

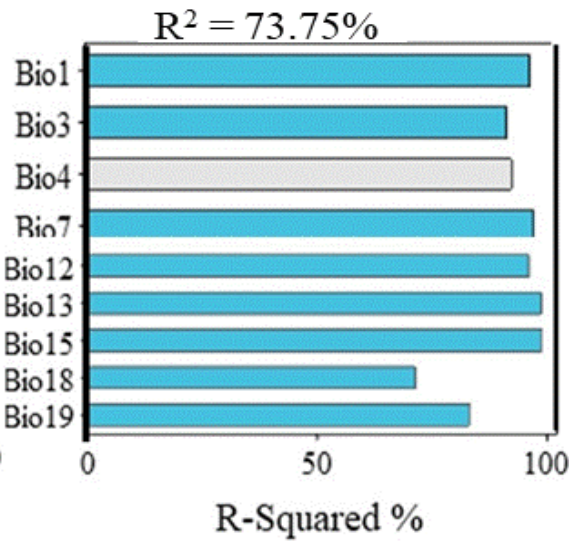

c) RCP 8.5

Note: the gray bars indicate the variables that don't assist explain additional information in C. arabica distributions

Figure 4. Response and bioclimatic variable data's goodness of fit in regression model constructions

In the RCP8.5, the changes in informative factors of Bio3, Bio12, Bio13, Bio18, and Bio19 would be expected to exert an important pressure on $C$. arabica cultivation $(P<0.05)$. The probability values of coffee production were assessed to be 0.046, $-0.004,-0.007,-0.001$, and -0.001 for Bio3, Bio12, Bio13, Bio18, and Bio19, respectively. This implies that increasing each of those variables by one unit reduces the $C$. arabica cultivation by $4.6,2 \%, 0.4 \%, 0.7 \%, 0.1 \%$, and $0.1 \%$, respectively. However, the promising effects of climatological factors on coffee cultivation are expected as a result of an increase in Bio1, Bio4, Bio7, and Bio15. Once every climatology issue increases by one unit, $C$. arabica is expected to increase by $1.19 \%, 4.6 \%, 6.3 \%$, and $2 \%$, respectively, for Bio1, Bio4, Bio7, and Bio7 (Table 3).

Furthermore, the standardized regression weights, which disclose the standard deviation of the covariates, show that C. arabica reacted to predictive bioclimatic components unexpectedly. The values of standard regression weight for RCP4.5 were $0.07,0.47,0.51,0.22,-4.31,5.30,1.26,0.20$, and 0.18 for Bio1, Bio3, Bio4, Bio12, Bio13, Bio15, Bio18, and Bio19, respectively. Additionally, the standardized regression weights under RCP8.5 were estimated to be $0.20,0.78,0.77$, 0.73, 1.97, 2.91, 1.13, -0.35 , and -0.21 for Bio1, Bio3, Bio4, Bio12, Bio13, Bio15, Bio18, and Bio19 (Table 3).

\subsection{Optimization of bioclimatic variable for coffee (Coffea arabica L.) cultivation}

Fig. 5 shows the response lines or curves between $C$. arabica and explanatory factors for current and RCP4.5 and RCP8.5 climate change scenarios of the 2050s. The red line in each bio-climatic graph demonstrates the prerequisites of bioclimatic factors for optimum $C$. arabica production.

\subsubsection{Current response optimization}

The optimal setups of eligible factors for $C$. arabica cultivation are displayed in Table 4. Seven influential bioclimatic parameters such as Bio3, Bio4, Bio7, and Bio12, Bio15, Bio18, and Bio19 were optimized for response variables, while Bio1 and Bio13 were reserved from the model since they had no assisted information on the likelihood of coffee cultivation under present climate conditions. The five bio-climatic variables that increased the likelihood of $C$. arabica cultivation were as follows: $76.33-77.05 \%$ for Bio3, 1039-1085.27\% for Bio4, 19.77-20.05 ${ }^{\circ} \mathrm{C}$ for Bio7, 1649.18$1871 \mathrm{~mm}$ for Bio12, 61.63-67.03 for Bio15, 383.54$447.75 \mathrm{~mm}$ for Bio18, and 378.45-502.30mm for Bio19 (Table 4). The maximum probability distribution of $C$. arabica was achieved at $82 \%$ when all bioclimatic variables were measured concurrently at Bio3; $1075.01 \%$, Bio4; $20.09^{\circ} \mathrm{C}$, Bio7; $20.09^{\circ} \mathrm{C}$, Bio12; $1871.40 \mathrm{~mm}$, Bio1; 567.03\%, Bio1; $8436.21 \mathrm{~mm}$, and $502.37 \mathrm{~mm}$ of Bio19. If the parameters exceed or drop further beyond these indicated limits, the coffee crop distribution will be declined.

\subsubsection{Future response optimization}

The top five optimal values of bio-climatic factors for maximum C. arabica production (72-83\%) were also set under RCP4.5. The best values were estimated to be ranged between $22.50-23.17^{\circ} \mathrm{C}, 76-81 \%, 105.13-109.13 \%$, 17.53-20.07 ${ }^{\circ} \mathrm{C}, 1777.33-2192.67 \mathrm{~mm}, 319.3-376.33 \mathrm{~mm}$, and 587-813 mm, respectively, for Bio1, Bio3, Bio4, Bio7, Bio12, Bio15, and Bio19. When these important factors are combined, they significantly help to increase $C$. arabica production at certain optimal levels for each component. However, it will be disabled in areas where the predictors are less than or more than these optimum levels, as decided by this predefined study (Table 5). Bio13 and Bio18 are flimsy variables that had little or no effect on future $C$. arabica and were eliminated from the model early on (Fig. 4b).

Similarly, the values of bio-climatic variables that were closer to the optimal solution were estimated as optimal settings of the input variables for predicting $C$. arabica distribution under the RCP8.5, as shown in Table 6. The maximum estimated probability values of the $C$. arabica distribution ranging from $67-75 \%$ were estimated to be found in landscapes with $23.50-23.80^{\circ} \mathrm{C}$ of Bio1, $72.67-75.53 \%$ of Bio3, $19.20-19.90^{\circ} \mathrm{Cof}$ Bio7, $1685.67-1900 \mathrm{~mm}$ of Bio12, 315.33-343 mm of Bio13, 51.33-77.67\% of Bio15, 180-364.33 $\mathrm{mm}$ of Bio18, and 369-943.33 mm of Bio19. This implies that above or below these optimal values of these explanatory variables the $C$. arabica cultivation would be reduced. 

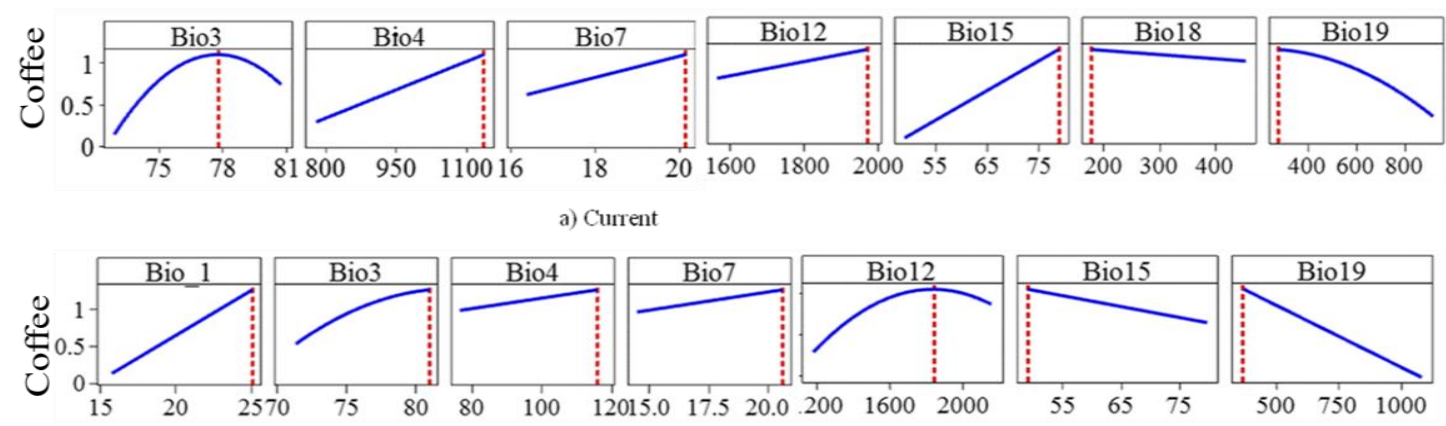

b) $\mathrm{RCP} 4.5$

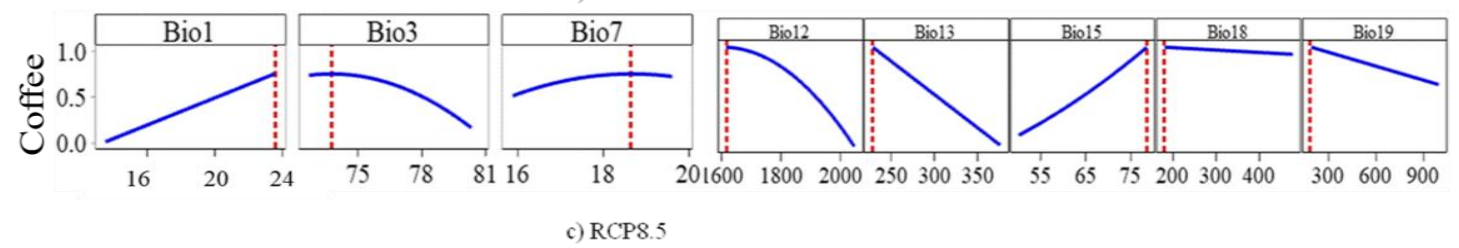

Note: the red lines indicate the variable optimal settings while blue lines show projected coffee at various bioclimatic variable settings

Figure 5: Optimum bioclimatic variables for coffee cultivation under various climate change scenarios

Table 4. The top five alternative optimum bioclimatic factors for C. arabica growth in the current state (1979-2013)

\begin{tabular}{ccccccccc}
\hline No & Bio3 $(\%)$ & Bio4 $(\%)$ & Bio7 $\left({ }^{\circ} \mathrm{C}\right)$ & Bio12 $(\mathrm{mm})$ & Bio15 $(\%)$ & Bio18 $(\mathrm{mm})$ & Bio19 (mm) & C. arabica \\
\hline $\mathbf{1}$ & $\mathbf{7 7 . 0 5}$ & $\mathbf{1 0 7 . 5}$ & $\mathbf{2 0 . 0 9}$ & $\mathbf{1 8 7 1 . 4}$ & $\mathbf{6 7 . 0 3}$ & $\mathbf{4 3 6 . 2 1}$ & $\mathbf{5 0 2 . 3}$ & $\mathbf{0 . 8 2}$ \\
$\mathbf{2}$ & 76.55 & 108.53 & 19.98 & 1737.49 & 62.59 & 415.02 & $\mathbf{3 7 8 . 4 5}$ & 0.77 \\
$\mathbf{3}$ & 76.67 & 105.53 & 19.95 & 1815.5 & 63.97 & 447.75 & 590.12 & 0.75 \\
4 & 76.33 & 105.03 & 20.05 & 1649.18 & 62.33 & 383.54 & 368.61 & 0.73 \\
5 & 76.52 & 103.96 & 17.70 & 1746.02 & 61.63 & 420.84 & 382.35 & 0.72 \\
\hline
\end{tabular}

Note: the bolded numbers are the values of explanatory variables that best suit for higher coffee production under the current climate change scenario

Table 5. The top five alternative optimum bioclimatic factors for C. arabica growth under the RCP4.5 (2041-2060)

\begin{tabular}{ccccccccc}
\hline No & Bio1 $\left({ }^{\circ} \mathrm{C}\right)$ & Bio3 $(\%)$ & Bio4 $(\%)$ & Bio7 $\left({ }^{\circ} \mathrm{C}\right)$ & Bio12 $(\mathrm{mm})$ & Bio15 $(\%)$ & Bio19 (mm) & C. arabica \\
\hline $\mathbf{1}$ & $\mathbf{2 2 . 7 3}$ & $\mathbf{7 7 . 0 0}$ & $\mathbf{1 0 8 . 0 7}$ & $\mathbf{1 9 . 9 0}$ & $\mathbf{1 8 5 0 . 3 3}$ & $\mathbf{7 1 . 0 0}$ & $\mathbf{5 8 7 . 0 0}$ & $\mathbf{0 . 8 3}$ \\
$\mathbf{2}$ & 22.80 & 76.33 & 109.13 & 20.03 & 1722.00 & 75.33 & 688.33 & 0.79 \\
3 & 22.97 & 76.67 & 106.17 & 19.83 & 1649.67 & 71.63 & 619.67 & 0.77 \\
4 & 23.17 & 76.33 & 105.13 & 20.07 & 1757.67 & 73.27 & 736.00 & 0.74 \\
5 & 22.50 & 81.00 & 100.70 & 17.53 & 1768.00 & 76.33 & 813.00 & 0.72 \\
\hline
\end{tabular}

Note: the bolded numbers are the values of explanatory variables that best suit for higher coffee production in the future 2050s under the RCP4.5 climate change scenario.

Under the RCP8.5 climate change scenarios, the Bio4 variable was estimated to be a non-significant contributor to the determination of $C$. arabica cultivation (Fig. 4C).

\subsection{Coffee (Coffea arabica L.) response comparison analyses}

Coffee arabica's response comparison among the targeted climate change scenarios analysis results is shown in Fig. 6. The five top logistic output mean values reveal that there are significant differences in $C$. arabica distribution in the three climate change scenarios $(P<0.05)$. The mean values of logistic output in \% were estimated to be 75.8, 77, and 70.2 , respectively, under the current, RCP4.5, and RCP8.5 climate change scenarios. The mean difference between
RCP4.5 and the current were $1.2 \%$, between RCP8.5 and RCP4.5 it was $6.8 \%$, and between RCP8.5 and current it was $5.6 \%$ (Fig. $6 \mathrm{~d}$, e, and f). The average value of $C$. arabica likelihood under RCP4.5 would be significantly higher than those under the current and RCP8.5 scenarios $(P=0.0003)$.

\section{DISCUSSIONS}

Because data inputs and methodological choices affect the dependability and usefulness of model predictions, it's critical to evaluate the model's accuracy and utility. In the present study, the Maxent was made to avoid data overfitting and underfitting and to have a low generalization error, which is a measure of how well it predicts. The precision with which Maxent and multiple regression models predict the 
association of $C$. arabica species and bioclimatic data was assessed. All reflected a better understanding of the relationship between inputs and outputs under the three climate scenarios: current and RCP4.5, and RCP8.5 of the next 2050s. The maxEnt model's threshold was significantly higher than the random model's threshold (0.5). It performed well (greater than $80 \%$ ) in distinguishing the presence and absence of the $C$. arabica species in all three scenarios. Total precipitation (Bio12), precipitation seasonality (Bio15), and annual mean temperature (Bio1) played a greater role in delivering the higher efficiency of the models. These results are consistent with numerous studies that found the Maxent Model's accuracy levels to be between $80 \%$ and $90 \%$ in various research areas (Angelieri et al., 2016; Padalia et al., 2014; Pramanik et al., 2018; Qin et al., 2017).

Present results also indicate that the recruited Path model for response analyses has the capability to successfully define the association between $C$. arabica and bioclimatic factors. The chi-square values were lower while the $p$-values were higher $(P>0.05)$ for each climatological test (Fig. 3). This suggests that the regression model is effective in explaining the association between $C$. arabica and bioclimatic variables. These model evaluation results are in line with the observations of Melesse (2014), who reported the chi-square statistics such as P-values of 0.894 and chi-squared of 0.018 in his dissertation.

The multiple regression model also successfully performed the response optimization for $C$. arabica with the bioclimatic factors. The R-square, which represents the degree of variation in the response variables, indicates that the combined explanatory variables explain more than $64 \%$ of the variation in the coffee itself in each climate change scenario. During response optimization, the variables like Bio1 and Bio13 in the current scenario, Bio13 and Bio18 in the RCP4.5 scenario, and Bio4 in the RCP8.5 scenario were dropped from the model as the results of the variables had no significant contribution to the model's goodness of fit (Fig. 4a, b, and c). The present model's goodness of fit is more efficient than the result of Yuvaraj (2020), which showed $46.3 \%$ coefficient of determination (R2) while applying a regression model for the responsiveness of land surface temperature to the Normalized Difference Vegetation Index (NDV) in North India using a regression model

The MaxEnt model's diagnostic results indicate that total precipitation (Bio12), precipitation seasonality (Bio15), and annual mean temperature (Bio1) were shown to have a greater impact on current $C$. arabica than any other variables.

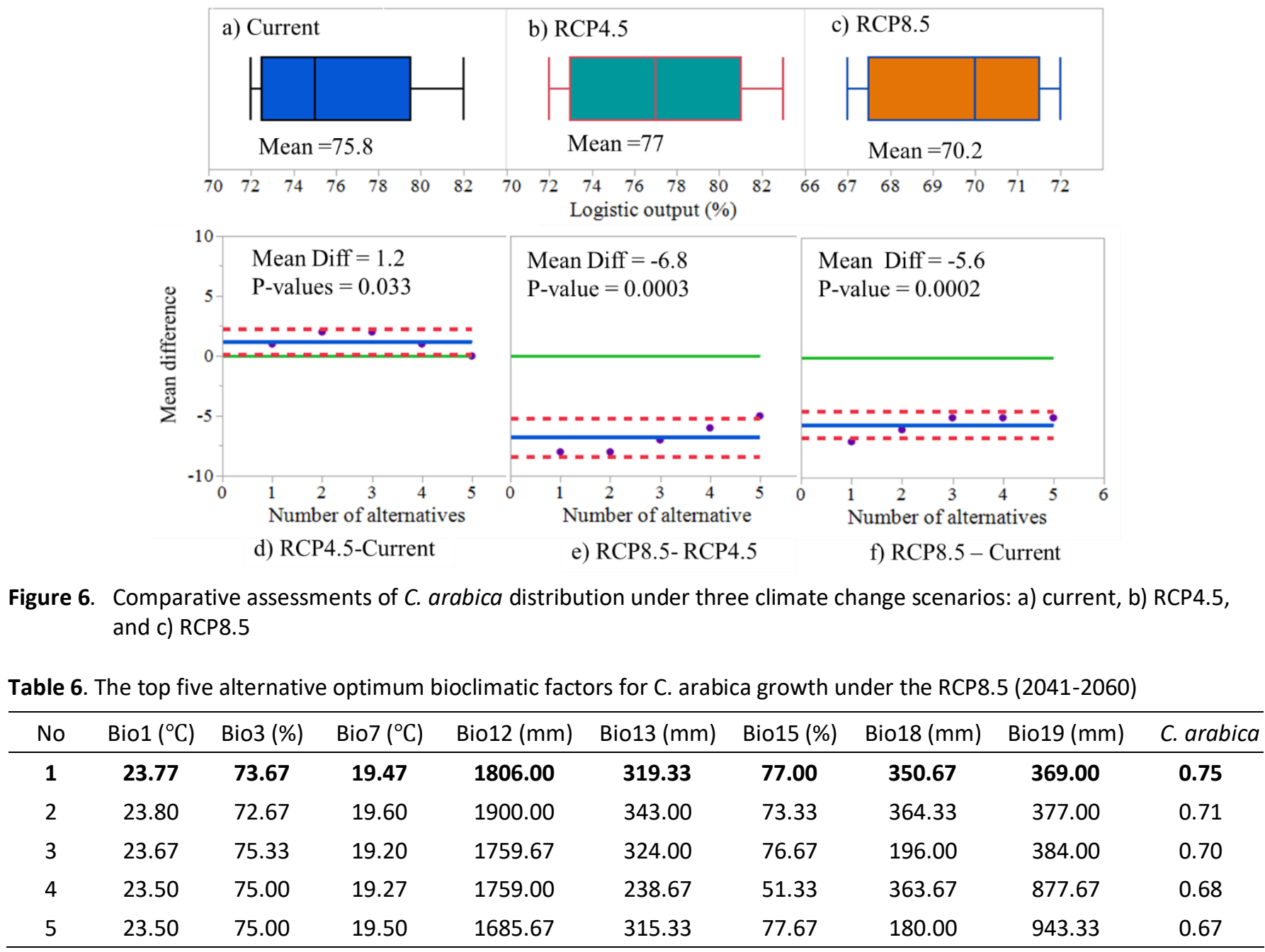

Table 6. The top five alternative optimum bioclimatic factors for C. arabica growth under the RCP8.5 (2041-2060)

Note: the bolded numbers indicate values of explanatory variables that best suit for higher coffee production in the future 2050s under the RCP8.5 climate change scenarios 
The distribution of possible habitats for $C$. arabica in its native regions was mostly determined by total precipitation. The present results coincide with the report of Abolmaali et al. (2018), who used the maximum entropy model to discover that the two precipitation (Bio12 and Bio19) and two temperature (Bio5 and Bio8) variables, notably elevation, are the most representative variables in regions of concern for vulnerable Daphne mucronata plant species habitats in central Iran. According to Chemura et al. (2016), precipitation-related factors were more relevant in evaluating suitability for coffee cultivation in Zimbabwe's eastern highlands. Over $70 \%$ of the climate suitability of $C$. arabica was determined by two precipitation-related variables (Bio15 and Bio19) in eastern Zimbabwe

According to the response analysis, changes in each bioclimatic variable had a substantial influence on $C$. arabica cultivation under present and future climate conditions. The rising extreme precipitation factors (Bio18 and Bio19) significantly declined $C$. arabica cultivation, although the rising two precipitation-related variables (Bio12 and Bio15) and two temperature-related variables (Bio4, and Bio7) significantly improved it during the last three decades. Similarly, despite somewhat predicted climate change prevention and adaptation measures under RCP4.5 scenarios, changes in precipitation-related factors are expected to be the most limiting factor in $C$. arabica production in the future 2050s. Three precipitation-related factors (Bio15, Bio18, and Bio19) will continue to negatively affect $C$. arabica cultivation under RCP4.5, whereas four temperature-related variables (Bio1, Bio3, Bio4, and Bio7), as well as two precipitations (Bio12 and Bio13), will have a significant beneficial impact (Table 3). Furthermore, in the RCP8.5 climate change scenario, increases in precipitation-related factors (Bio12, Bio13, Bio18, and Bio19) as well as isothermality (Bio3) will dramatically reduce $C$. Arabic, although temperature-related variables (Bio1 and Bio7) and precipitation seasonality (Bio15) are projected to have a favorable effect on the coffee crop distribution.

Despite the scarcity of data on C. arabica's responses to each bioclimatic factor, several studies have found that current and future climate conditions pose a threat to $C$. arabica cultivation in subtropical and tropical zones. The present results are consistent with those reported by Iscaro (2014), who studied the impact of climate change on coffee production in Colombia and Ethiopia. Because $C$. arabica has such particular growing needs, even little variations in temperature and precipitation might destroy the plant. The health of these coffee species in Colombia is being jeopardized by increased rainfall, while rapidly rising temperatures are killing vegetation at an alarming pace in Ethiopia. The results of (Moat et al., 2017), who studied Ethiopia's coffee sector resilience potential in coffee-growing zones, reported that precipitation-related variables (Bio12 and Bio15), as well as annual mean temperature (Bio1), are the most determinantal factors of $C$. arabica's adaptability to climate change. In the absence of considerable interventions by the 2080s, the dispersion potential of the coffee plant will be lowered by $39 \%-59 \%$, according to this assessment. These results are also consistent with those of Wang et al. (2015), who found that $C$. arabica species in Uganda's east, southeast, and northwest areas will be negatively affected by the seasonality of precipitation (Bio115) and annual mean temperature (Bio1). The results of Abdelaal et al. (2019), Chemura et al. (2016), and Mighty (2015) emphasize that the annual average temperature and total precipitation, which are the most critical determinants in defining climatic suitability for coffee production, appear to be very important to the crop plant's production.

The current research also sought to determine the optimum settings for joint bioclimatic factors that are needed for $C$. arabica production under each climate change scenario. Table 7 shows the maximum possibility of coffee cultivation under present and future climate change scenarios, with the minimum and maximum ranges placed between them. The higher possibility of $C$. arabica cultivation (72\%-82\%) was observed in coffee-producing landscapes with total precipitation of $1746-1871.4 \mathrm{~mm}$, annual temperature ranges of $17.10-20.09^{\circ} \mathrm{C}$, and other precipitation and temperaturerelated variables (Table 4). However, there was no significant impact of the annual mean temperature (Bio1) on coffee cultivation under current climatic conditions (Table 4).

A combination of bioclimatic factors given in Table 7, including an annual mean temperature range of $22.5-22.73^{\circ} \mathrm{C}$ and total precipitation of $1768.33-1850.33 \mathrm{~mm}$, will be

Table 7. Optimal multiple responses of $C$. arabica to bioclimate factors; current, RCP4.5 and RCP8.5 scenarios

\begin{tabular}{|c|c|c|c|c|c|c|}
\hline \multirow{2}{*}{ Variables } & \multicolumn{2}{|c|}{ Current } & \multicolumn{2}{|c|}{ RCP4.5 } & \multicolumn{2}{|c|}{ RCP8.5 } \\
\hline & Lower & Upper & Lower & Upper & Lower & Upper \\
\hline $\operatorname{Bio} 1\left({ }^{\circ} \mathrm{C}\right)$ & - & - & 22.50 & 22.73 & 23.50 & 23.77 \\
\hline Bio3 (\%) & 76.52 & 77.05 & 77.00 & 81.00 & 73.67 & 75.00 \\
\hline Bio4(\%) & 103.96 & 107.50 & 100.70 & 108.07 & - & - \\
\hline $\operatorname{Bio} 7\left({ }^{\circ} \mathrm{C}\right)$ & 17.11 & 20.09 & 17.53 & 19.90 & 19.50 & 19.47 \\
\hline $\operatorname{Bio12}(\mathrm{mm})$ & 1746 & 1871.40 & 1768.33 & 1850.33 & 1685.67 & 1806.00 \\
\hline $\operatorname{Bio13}(\mathrm{mm})$ & - & - & - & - & 315.33 & 319.33 \\
\hline Bio15 (\%) & 67.03 & 61.63 & 71.00 & 76.33 & 77.00 & 77.67 \\
\hline $\operatorname{Bio18}(\mathrm{mm})$ & 420.84 & 436.21 & - & - & 180.00 & 350.67 \\
\hline Bio19 (mm) & 502.30 & 382.35 & 587.00 & 813.00 & 943.33 & 369.00 \\
\hline Logistic output (\%) & 72.00 & 82.00 & 72.00 & 83.00 & 67.00 & 75.00 \\
\hline
\end{tabular}


required to keep $C$. arabica production at $72-83 \%$ under RCP4.5 climate scenarios. This is expected to be significantly higher than those under the current and RCP8.5 scenarios ( $P$ $=0.0003)$. This means that implementing medium-scale climate change mitigation and adaptation strategies such as efficient shade management, irrigation, and mulching (Moat et al., 2017) will favor the cultivation of this type. However, under the RCP8.5 scenarios, an annual mean temperature of $23.5-23.77^{\circ} \mathrm{C}$ and total precipitation of $1685.67-1806.67$ are projected to be required for the highest likelihood of $C$. arabica cultivation (67-77\%). From these perspectives, it's simple to see how precipitation and temperature rise under RCP8.5 are expected to decline coffee farming in the next 2050s, compared to current climatic conditions. The current results are inconsistent with the results of Bunn (2015), who established that $C$. arabica thrives best in tropical regions with annual temperatures ranging from $17^{\circ} \mathrm{C}$ to $23^{\circ} \mathrm{C}$ and rainfall ranging from 800 to $1200 \mathrm{~mm}$ but coincide with those reported by Moat et al. (2017), who discovered that an optimal mean annual temperature of 18 to $21^{\circ} \mathrm{C}$ and a total annual rainfall of $1200-$ to- $1800 \mathrm{~mm}$ will be required for $C$. arabica coffee species cultivation in the tropical highland of Ethiopia.

When compared to the current and RCP8.5 climate conditions, the likelihood of the distribution of $C$. arabica will rise by $1.2 \%$ and $6.8 \%$, respectively, under RCP4.5. However, as compared to the present and RCP4.5, the crop distribution in RCP8.5 is anticipated to decrease by $5.6 \%$ and $6.8 \%$, respectively. As precipitation and temperature-related factors rise, the ability of $C$. arabica to cultivate will diminish unless mitigation and adaptation measures are applied. Based on their findings, Davis et al. (2012) predicted that $C$. arabica would fall by $38 \%$ in the most favorable area and $90 \%$ in the least favorable area in Ethiopia in the 2080s.

\section{CONCLUSIONS}

Coffee distribution modeling can give significant insight into the expected response of $C$. arabica to the target climatic factors. There is a considerable variation in the $C$. arabica species' reactions to bio-climatic factors under current and future climate change scenarios, resulting in a significant fluctuation in the crop's cultivation. In this study, C. arabica has negatively responded to the increase in precipitation in the warmest and coldest quarters, which continued to significantly reduce the distribution of coffee crops in each targeted climate change scenario, but favorably responded to annual temperature range ranges (Bio7). In comparison to the current situation, crop cultivation in RCP4.5 is expected to be much higher, but crop cultivation in RCP8.5 is expected to be significantly lower. As a result, the cultivation of $C$. arabica will increase by $1.2 \%$ under RCP4.5 but decrease by $5.6 \%$ under RCP8.5, as precipitation and temperature-related variables increase.

Researchers have used limited models and bioclimatic factors to estimate the climate change implications of $C$. arabica using bioclimatic modeling, but a more comprehensive analysis is needed to make an accurate prediction of future outcomes using different models and other environmental factors.

\section{Declaration of competing interest}

The authors declare no competing financial or personal interests that may appear and influence the work reported in this paper.

\section{References}

Abdelaal, M., Fois, M., Fenu, G., \& Bacchetta, G. (2019). Using MaxEnt modeling to predict the potential distribution of the endemic plant Rosa arabica Crép. in Egypt. Ecological Informatics, 50, 68-75. https://doi.org/10.1016/j.ecoinf.2019.01.003

Abolmaali, S. M.-R., Tarkesh, M., \& Bashari, H. (2018). MaxEnt modeling for predicting suitable habitats and identifying the effects of climate change on a threatened species, Daphne mucronata, in central Iran. Ecological Informatics, 43, 116-123. https://doi.org/10.1016/j.ecoinf.2017.10.002

Aderolu, I. A., Babalola, F. D., Ugioro, O., Anagbogu, C. F., Ndagi, I., Mokwunye, F. C., Mokwunye, I. U., Idrisu, M., \& Asogwa, E. U. (2014). Production and marketing of Coffee (Coffea robusta) in Kogi State, Nigeria: Challenges and recommendation for intervention. JOURNAL OF SOCIAL SCIENCE RESEARCH, 3(2), 207215. https://doi.org/10.24297/jssr.v3i2.3559

Alemayehu, M. (2015). Ethiopian Highlands: Home for Arabica Coffee (Coffea arabica L.). In Tropical lakes in a changing environment: water, land, biology, climate and humans (pp. 58-65). https://www.researchgate.net/profile/MelkamuWorkie/publication/317231826_Ethiopian_Highlands _Home_for_Arabica_Coffee_Coffea_arabica_L/links/ 592d1b0f0f7e9b9979̈b3a3da/Ethiopian-HighlandsHome-for-Arabica-Coffee-Coffea-arabica-L.pdf

Amamo, A. A. (2014). Coffee production and marketing in Ethiopia. Eur J Bus Manag, 6(37), 109-122. https://www.iiste.org/Journals/index.php/EJBM/artic le/view/18697

Angelieri, C. C. S., Adams-Hosking, C., Ferraz, K. M. P. M. d. B., de Souza, M. P., \& McAlpine, C. A. (2016). Using Species Distribution Models to Predict Potential Landscape Restoration Effects on Puma Conservation. PLOS ONE, 11(1), e0145232. https://doi.org/10.1371/journal.pone.0145232

Bliss, S. (2017). Coffee Biomes. Geography Bulletin, 49(4), 2941.

https://www.gtansw.org.au/files/geog_bulletin/2017 /4_2017/06_GTA\%20NSW\%20Bulletin_Issue\%204_20 17_Coffee\%20Biomes.pdf

Boria, R. A., Olson, L. E., Goodman, S. M., \& Anderson, R. P. (2014). Spatial filtering to reduce sampling bias can improve the performance of ecological niche models. Ecological Modelling, 275, 73-77. https://doi.org/10.1016/j.ecolmodel.2013.12.012

Brázdil, R., Trnka, M., Mikšovský, J., Řezníčková, L., \& Dobrovolný, P. (2015). Spring-summer droughts in the Czech Land in 1805-2012 and their forcings. International Journal of Climatology, 35(7), 14051421. https://doi.org/10.1002/joc.4065 
Brown, J. L., Hill, D. J., Dolan, A. M., Carnaval, A. C., \& Haywood, A. M. (2018). PaleoClim, high spatial resolution paleoclimate surfaces for global land areas. Scientific Data, 5(1), 180254 https://doi.org/10.1038/sdata.2018.254

Bunn, C. (2015). Modeling the climate change impacts on global coffee production [Dissertation, HumboldtUniversität zu Berlin, Lebenswissenschaftliche Fakultät]. https://doi.org/10.18452/17349

Camargo, M. B. P. d. (2010). The impact of climatic variability and climate change on arabic coffee crop in Brazil. Bragantia, 69(1),

239-247. https://doi.org/10.1590/S0006-87052010000100030

Chauhan, R., Hooda, M., \& Tanga, A. A. (2015). Coffee: the backbone of Ethiopian economy. International Journal of Economic Plants, 1(2), 82-86. http://pphouse.org/upload_article/83447731_6_IJEP _February_2015_Chauhan_et_al.pdf

Chemura, A., Kutywayo, D., Chidoko, P., \& Mahoya, C. (2016). Bioclimatic modelling of current and projected climatic suitability of coffee (Coffea arabica) production in Zimbabwe. Regional Environmental Change, 16(2), 473-485. https://doi.org/10.1007/s10113-015-0762-9

Chiou, C.-R., Hsieh, T.-Y., \& Chien, C.-C. (2015). Plant bioclimatic models in climate change research. Botanical Studies, 56(1), 26. https://doi.org/10.1186/s40529-015-0104-8

Coffee: World Markets and Trade. (2019). World Agricultural Outlook Board/USDA. https://downloads.usda.library.cornell.edu/usdaesmis/files/m900nt40f/xk81jw68v/kp78gs60d/coffee. pdf

Cuneen, J., \& Tobar, D. (2015). Chi-square Tests. In Sport Industry Research and Analysis: An Approach to Informed Decision Making. Routledge, New York. https://doi.org/10.4324/9781315212944-28

Davis, A. P., Gole, T. W., Baena, S., \& Moat, J. (2012). The Impact of Climate Change on Indigenous Arabica Coffee (Coffea arabica): Predicting Future Trends and Identifying Priorities. PLOS ONE, 7(11), e47981. https://doi.org/10.1371/journal.pone.0047981

Deribe, H. (2019). Review on Factors which Affect Coffee (Coffea Arabica L.) Quality in South Western, Ethiopia. International Journal of Forestry and Horticulture, 5(1), 12-19. https://doi.org/10.20431/2454-9487.0501003

Diro, S., Erko, B., \& Yami, M. (2019). Cost of Production of Coffee in Jimma Zone, Southwest Ethiopia. Ethiopian Journal of Agricultural Sciences, 29(3), 13-28. https://www.ajol.info/index.php/ejas/article/downlo ad/189554/178783

Fick, S. E., \& Hijmans, R. J. (2017). WorldClim 2: new 1 - km spatial resolution climate surfaces for global land areas. International Journal of Climatology, 37(12), 4302-4315. https://doi.org/10.1002/joc.5086

Funk, C. C., Rowland, J., Eilerts, G., Kebebe, E., Biru, N., White, L., \& Galu, G. (2012). A climate trend analysis of Ethiopia [Report](2012-3053). (Fact Sheet, Issue. U. S. G. Survey. http://pubs.er.usgs.gov/publication/fs20123053
Gelman, A., Goodrich, B., Gabry, J., \& Vehtari, A. (2019). Rsquared for Bayesian Regression Models. The American Statistician, 73(3), 307-309. https://doi.org/10.1080/00031305.2018.1549100

Gray, S. B., \& Brady, S. M. (2016). Plant developmental responses to climate change. Developmental Biology, 419(1), https://doi.org/10.1016/j.ydbio.2016.07.023

Halligan, S., Altman, D. G., \& Mallett, S. (2015). Disadvantages of using the area under the receiver operating characteristic curve to assess imaging tests: A discussion and proposal for an alternative approach. European Radiology, 25(4), 932-939. https://doi.org/10.1007/s00330-014-3487-0

Intergovernmental Panel on Climate Change. (2014). Climate Change 2013 - The Physical Science Basis: Working Group I Contribution to the Fifth Assessment Report of the Intergovernmental Panel on Climate Change. Cambridge University Press. https://doi.org/DOI: 10.1017/CBO9781107415324

Iscaro, J. (2014). The impact of climate change on coffee production in Colombia and Ethiopia. Global Majority E-Journal, 5(1), 33-43. http://bangladeshstudies.org/files/Global_Majority_e _Journal_5_1.pdf\#page=33

Karger, D. N., Conrad, O., Böhner, J., Kawohl, T., Kreft, H., Soria-Auza, R. W., Zimmermann, N. E., Linder, H. P., \& Kessler, M. (2017). Climatologies at high resolution for the earth's land surface areas. Scientific Data, 4(1), 170122. https://doi.org/10.1038/sdata.2017.122

Kwon, Y., Lee, T., Lang, A., \& Burnette, D. (2019). Assessment on latitudinal tree species richness using environmental factors in the southeastern United States. PeerJ, 7, e6781. https://doi.org/10.7717/peerj.6781

Mas, J.-F., Soares Filho, B., Pontius, R. G., Farfán Gutiérrez, M., \& Rodrigues, H. (2013). A Suite of Tools for ROC Analysis of Spatial Models. ISPRS International Journal of Geo-Information, 2(3), 869-887. https://doi.org/10.3390/ijgi2030869

McHugh, M. L. (2013). The chi-square test of independence. Biochemia medica, 23(2), 143-149. https://doi.org/10.11613/BM.2013.018

Melesse, S. F. (2014). Covariates and latents in growth modelling [Doctoral dissertation, University of Kwazulu-Natal]. http://hdl.handle.net/10413/11825

Mighty, M. A. (2015). Site suitability and the analytic hierarchy process: How GIS analysis can improve the competitive advantage of the Jamaican coffee industry. Applied Geography, 58, 84-93. https://doi.org/10.1016/j.apgeog.2015.01.010

Minten, B., Stifel, D., \& Tamru, S. (2014). Structural Transformation of Cereal Markets in Ethiopia. The Journal of Development Studies, 50(5), 611-629. https://doi.org/10.1080/00220388.2014.887686

Moat, J., Williams, J., Baena, S., Wilkinson, T., Gole, T. W., Challa, Z. K., Demissew, S., \& Davis, A. P. (2017). Resilience potential of the Ethiopian coffee sector 
under climate change. Nature Plants, 3(7), 17081. https://doi.org/10.1038/nplants.2017.81

Moore, D. S. (2001). The Basic Practice of Statistics. Technometrics, 43(3), 381-381. https://doi.org/10.1198/tech.2001.s639

Moraes, G. A. B. K., Chaves, A. R. M., Martins, S. C. V., Barros, R. S., \& DaMatta, F. M. (2010). Why is it better to produce coffee seedlings in full sunlight than in the shade? A morphophysiological approach. Photosynthetica, 48(2), 199-207. https://doi.org/10.1007/s11099-010-0025-4

National Meteorological Services Agency. (2005). Agrometeorological bulletin. Seasonal Agro Meteorological Bulletin, 15(3), 1-19. http://www.wamis.org/countries/ethiopia/Eth20051 503.pdf

O'Donnel, M. S., \& Ignizio, D. A. (2012). Bioclimatic predictors for supporting ecological applications in the conterminous United States [Report](691). (Data Series, Issue. U. S. G. Survey. http://pubs.er.usgs.gov/publication/ds691

Padalia, H., Srivastava, V., \& Kushwaha, S. P. S. (2014). Modeling potential invasion range of alien invasive species, Hyptis suaveolens (L.) Poit. in India: Comparison of MaxEnt and GARP. Ecological Informatics, 22, 36-43. https://doi.org/10.1016/j.ecoinf.2014.04.002

Paquit, J. (2019). Maxent Modeling Training Manual in ArcGIS 10. https://doi.org/10.13140/RG.2.2.21119.97448

Pearson, R. G., \& Dawson, T. P. (2003). Predicting the impacts of climate change on the distribution of species: are bioclimate envelope models useful? Global Ecology and Biogeography, 12(5), 361-371. https://doi.org/10.1046/j.1466-822X.2003.00042.x

Phillips, S. J., Anderson, R. P., Dudík, M., Schapire, R. E., \& Blair, M. E. (2017). Opening the black box: an opensource release of Maxent. Ecography, 40(7), 887-893. https://doi.org/10.1111/ecog.03049

Phillips, S. J., \& Dudík, M. (2008). Modeling of species distributions with Maxent: new extensions and a comprehensive evaluation. Ecography, 31(2), 161-175. https://doi.org/10.1111/j.0906-7590.2008.5203.x

Pohlan, H. A. J., \& Janssens, M. J. J. (2010). Growth and Production of Coffee. In W. H. Verheye (Ed.), Soils, Plant Growth and Crop Production. UNESCOEncyclopedia of Life Support System. https://www.eolss.net/ebooklib/bookinfo/soilsplant-growth-crop-production.aspx\#

Potopová, V., Štěpánek, P., Možný, M., Türkott, L., \& Soukup, J. (2015). Performance of the standardised precipitation evapotranspiration index at various lags for agricultural drought risk assessment in the Czech Republic. Agricultural and Forest Meteorology, 202, 26-38.

https://doi.org/10.1016/j.agrformet.2014.11.022

Pramanik, M., Paudel, U., Mondal, B., Chakraborti, S., \& Deb, P. (2018). Predicting climate change impacts on the distribution of the threatened Garcinia indica in the Western Ghats, India. Climate Risk Management, 19,
94-105.

https://doi.org/https://doi.org/10.1016/j.crm.2017.1 1.002

Qin, A., Liu, B., Guo, Q., Bussmann, R. W., Ma, F., Jian, Z., Xu, G., \& Pei, S. (2017). Maxent modeling for predicting impacts of climate change on the potential distribution of Thuja sutchuenensis Franch., an extremely endangered conifer from southwestern China. Global Ecology and Conservation, 10, 139-146. https://doi.org/https://doi.org/10.1016/j.gecco.2017. 02.004

Samper, L. F., \& Quiñones-Ruiz, X. F. (2017). Towards a Balanced Sustainability Vision for the Coffee Industry. Resources, 6(2). https://doi.org/10.3390/resources6020017

Somarriba, E., \& López Sampson, A. (2018). Coffee and Cocoa Agroforestry Systems: Pathways to Deforestation, Reforestation, and Tree Cover Change. In LEAVES Leveraging Agricultural Value Chains to Enhance Tropical Tree Cover and Slow Deforestation. International Bank for Reconstruction and Development / The World Bank https://doi.org/10.13140/RG.2.2.29700.78724

Song, B., Niu, S., \& Wan, S. (2016). Precipitation regulates plant gas exchange and its long-term response to climate change in a temperate grassland. Journal of Plant Ecology, 9(5), 531-541. https://doi.org/10.1093/jpe/rtw010

Steffen, W., Rice, M., Hughes, L., \& Dean, A. (2018). The good, the bad and the ugly: limiting temperature rise to $1.5^{\circ} \mathrm{C}$. https://www.climatecouncil.org.au/wpcontent/uploads/2018/10/CC-IPCC-report-1.pdf

Svoboda, M. D., \& Fuchs, B. A. (2017). Handbook of Drought Indicators and Indices. In D. A. Wilhite \& R. S. Pulwarty (Eds.), Drought and Water Crises: Integrating Science, Management, and Policy (2nd ed.). CRC Press. https://doi.org/10.1201/b22009

USDA Foreign Agricultural Service. (2019). Ethiopia Coffee Annual Coffee Annual Report. G. A. I. Network. https://apps.fas.usda.gov/newgainapi/api/report/do wnloadreportbyfilename?filename=Coffee\%20Annual _Addis\%20Ababa_Ethiopia_5-29-2019.pdf

Vegro, C. L. R., \& de Almeida, L. F. (2020). Chapter 1 - Global coffee market: Socio-economic and cultural dynamics. In L. F. de Almeida \& E. E. Spers (Eds.), Coffee Consumption and Industry Strategies in Brazil (pp. 319). Woodhead Publishing. https://doi.org/10.1016/B978-0-12-814721-4.000019

Wan, P., \& Davis, R. A. (2020). Goodness-of-fit testing for time series models via distance covariance. Journal of Econometrics. https://doi.org/10.1016/j.jeconom.2020.05.008

Wang, N., Jassogne, L., van Asten, P. J. A., Mukasa, D., Wanyama, I., Kagezi, G., \& Giller, K. E. (2015). Evaluating coffee yield gaps and important biotic, abiotic, and management factors limiting coffee production in Uganda. European Journal of Agronomy, 63, 1-11. https://doi.org/10.1016/j.eja.2014.11.003 
Wang, X., Jiang, B., \& Liu, J. S. (2017). Generalized R-squared for detecting dependence. Biometrika, 104(1), 129139. https://doi.org/10.1093/biomet/asw071

Woldesenbet, A. G., Woldeyes, B., \& Chandravanshi, B. S. (2015). Wet coffee processing waste management practice in Ethiopia. Asian Journal of Science and Technology, http://www.journalajst.com/sites/default/files/issues -pdf/Dwonload\%202205.pdf

Yuvaraj, R. M. (2020). Extents of Predictors for Land Surface Temperature Using Multiple Regression Model. The Scientific World Journal, 2020, 3958589. https://doi.org/10.1155/2020/3958589 